\title{
Spatial Cultures of Soho, London Exploring the Evolution of Space, Culture, and Society of London's Infamous Cultural Quarter
}

\author{
Aditya VINOD-BUCHINGER, University College London, United Kingdom \\ Sam GRIFFITHS, University College London, United Kingdom
}

\begin{abstract}
Space as affording social interaction is highly debated subject among various epistemic disciplines. This research contributes to the discussion by shedding light on urban culture and community organisation in spatialised ways. Providing a case of London's famous cultural quarter, Soho, the research investigates the physical and cultural representation of the neighbourhood and relates it to the evolving socio-spatial logic of the area. Utilising analytical methods of space syntax and its network graph theories that are based on the human perception of space, the research narrates the evolution in spatial configuration and its implication on Soho's social morphology. The method used examines the spatial changes over time to evaluate the shifting identity of the area that was in the past an immigrant quarter and presently a celebrated gay village. The approach, therefore, combines analytical methods, such as network analysis, historical morphology analysis and distribution of land uses over time, with empirical methods, such as observations, auto-ethnography, literature, and photographs. Dataset comprises of street network graphs, historical maps, and street telephone and trade directories, as well as a list of literature, and data collected by the author through surveys.

Soho's cosmopolitanism and its ability to reinvent over time, when viewed through the prism of spatial cultures, help understand the potential of urban fabric in maintaining a time-space relationship and organisation of community life. Social research often tends to overlook the relationship between people and culture with their physical environment, where they manifest through the various practices and occupational distribution. In the case of Soho, the research found that there was a clear distribution of specific communities along specific streets over a certain period in the history. The gay bars were situated along Rupert and Old Compton Street, whereas the Jewish and Irish traders were established on Berwick Street, and so on. Upon spatial analysis of Soho and its surrounding areas, it was found that the streets of Soho were unlike that of its surrounding neighbourhoods. In Soho, the streets were organised with a certain level of hierarchy, and this hierarchy also shifted over time. This impacted the distribution of landuses within the area over time. Street hierarchy was measured through mathematical modelling of streets as derived by space syntax. In doing so, the research enabled viewing spaces and communities as evolving in parallel over time.

In conclusion, by mapping the activities and the spatiality of Soho's various cultural inhabitants over three historical periods and connecting these changes to the changing spatial morphology of the region, the research highlighted the importance of space in establishing the evolving nature of Soho. Such changes are visible in both symbolic and functional ways, from the location of a Govinda temple on a Soho square street, to the rise and fall of culture specific landuses such as gay bars on Old Compton Street. The research concludes by highlighting gentrification as an example of this time-space relation and addresses the research gap of studying spaces for its ability to afford changeability over time.
\end{abstract}

\section{Keywords}

Space syntax, Spatial cultures, Landuse, Data analysis, Mathematical Model, GIS 


\section{Introduction}

\subsection{Historical background}

Soho is London's historic cultural quarter and benefits from being positioned centrally in London. On its periphery, it is bound by high streets Oxford Street, Regent Street, Shaftesbury Avenue and Charring Cross Road. A total area of $2.6 \mathrm{sq} . \mathrm{km}$, it is part of Borough of City of Westminster and located towards the west side popularly known as the 'west-end'. Tourists and Londoners alike visit Soho and dwell in its many charms such as music, heritage, people, culture, bars, restaurants, cafes, clubs, gigs, venues, theatre, retail, alternate movement, and so on. Soho has become in some senses a pilgrimage site for the LGBTQ+ community, and has evolved since the 2000's to become the 'Gay Village of London' (Collins, 2004). There is a large concentration of amenities for the queer community concentrated along Old Compton Street (Vinod-Buchinger, 2018).

In Soho's spatial history, the beginning of some form of boundary making occurred around c. 1676. Most of Soho's streets take form from this original distribution of land, divided into long narrow plots along the North-South direction where its boundary on east and west sides became the present-day streets. Since the early years of 17th century, Soho has been welcoming immigrants from Europe and other parts of the world. The China Town, Greek street, the Govinda Temple, Synagogue can all be regarded as the impressions of its cosmopolitan past. 'The foreign immigrants, most of them the French, came amidst this wide spread building development and began to settle here' (Sheppard, 1966, p. 5). By the late 19th century, Soho ceased to be primarily French and became cosmopolitan. These new immigrants included the Germans and Italian, Swiss, Polish and Russian Jews, Turkish, Indians, Bangladeshis and Irish immigrants, and also a large exodus of British population. (Sheppard, 1966, p. 11).

These communities lived, worked, and traded in the surroundings. The Italians set up businesses along Old Compton Street, many Afghan and Turkish traders sold goods, nuts and garments/fabric at Berwick Street market, the French pastry shops (Patisserie Valerie), English and Irish butchers, the Hindu Temple on Soho Street, the St. Patrick Church for the Irish on Soho square, the French Protestant church on Soho Square are all reminiscent of these early immigrants. These venues were frequented by French revolutionaries, members of the literary society, and others. With the partial decriminalisation of homosexuality in 1967, another revolution took over Soho: 'the queers'. Old Compton street earlier known for their Italian restaurants now become the centre point of the queers. Since the 2000's as queer culture became more outward, open, and visual, the identity of this street evolved, and Soho became the famous gay village of London. The spirit of Soho mural on Carnaby street accurately captures this essence. This is the culture of the space transforming and reincarnating to something new. These multiple groups and their differences transformed a small neighbourhood into many identities, and Soho somehow binds the differences as they coexist here having established their authority of the area.

\subsection{Temporality in Soho's identity}

These groups organised themselves in their habituation, work and worship around certain specific streets in the early years of the settlement. As though each street would have been a quarter in its own sense, where various cultures and sub-cultures were organised through certain pattern of spatial clustering. Soho underwent various transformations over time evolving from an early Victorian immigrant settlement to the flamboyant cultural quarter, and now the gay village of modern-day London. The research is interested in exploring the pattering of the physical space investigating the influence it may have had on social interactions to assist in these identify transformations.

Why has Soho not evolved to become the China Town of London, although China Town is also at proximity and within its boundaries. Chinese and Asian supermarkets, restaurants, cafes and shops can 
be found mostly along Gerrard Street located next to each other in China Town. And Gay venues along Old Compton Street. The research investigates the spatiality of the streets to syntactically explain this process. What makes Soho a transforming and unique Urban village of all sorts. And has this been afforded by the its spatial configuration? Clustering, according to spatial theorists Bill Hillier et.al, is a spatial phenomenon (Hillier and Vaughan, 2007). But social, economic or design research have not been focusing of the network as affording any social value. This research, however, analyses the spatial network and build-environment to identify if the spatial connectivity of the area has changed over time, to find correlation to these social changes.

\subsection{Space in its Physical Sense - A space syntax approach}

To investigate the spatiality in its physical sense, it is pertinent to understand the propositions by Hillier and cohort on the three notions of space in cities - cities as generic with a dual grid, cities as movement economies, and cities as socio-spatial artefacts. Hillier (2016) addresses cities as a dual system of microeconomic and socio-cultural activities. Cities are generic, in the sense, where the street network that links the buildings which make up the city, is a dual system of inter-related networks, foreground and background. Foreground of smaller but longer lines with route continuity and background of larger number of shorter lines with more localised connections (Hillier, 2016, p. 200). Foreground network where social relations are produced which generate micro-economic activities, and background where it is reproduced that is primarily residential functions (socio-cultural functions).

Table 1: Properties of a dual grid - Social and spatial networks model with measures (Hillier, 2016, p. 210)

\begin{tabular}{|l|l|l|l|l|l|l|}
\hline $\begin{array}{c}\text { form } \\
\text { function } \\
\downarrow\end{array}$ & $\begin{array}{l}\text { social } \\
\text { network }\end{array}$ & information & groups & space & process & $\begin{array}{l}\text { spatial } \\
\text { network }\end{array}$ \\
\hline stability & $\begin{array}{l}\text { dense } \\
\text { (community) }\end{array}$ & redundancy & spatial & local & $\begin{array}{l}\text { 'brownian' } \\
\text { type }\end{array}$ & $\begin{array}{l}\text { background, } \\
\text { sociocultural } \\
\text { residence }\end{array}$ \\
\hline morphogenesis & $\begin{array}{l}\text { sparse } \\
\text { (individual) }\end{array}$ & unexpected & knowledge & non-local & $\begin{array}{l}\text { 'levy-flight } \\
\text { type }\end{array}$ & $\begin{array}{l}\text { oreground, } \\
\text { micro- } \\
\text { economic }\end{array}$ \\
\hline
\end{tabular}

In cities as movement economies, Hillier (2007, p. 113) provides fundamental proposition that the structure of the urban grid, that is its spatial configuration, is the single determinant of urban movement, both vehicular and pedestrian. The spatial organisation generates a pattern of busier and quieter movement patterns. Hillier explains this in two theories: the theory of natural movement, which is the proportion of movement the urban grid by itself generates, and the theory of movement economy, where the spatial order of landuses are determined by this distribution of movement along quieter and busier streets. Some streets which have high potential of movement which induces co-presence and encounters and some other wise. It views urban grid of cities as movement economies that generate economic processes as well as spaces for social reproduction (Hillier, 2007, pp. 111-137).

The third proposition is that cities as socio-spatial artefacts, important to this project on community and identity, where Hillier suggests that individuals that form a community are part of at least one spatially defined group defined by their spatial continuity of some kind and spatial proximity of its members such as village or university and another transpatial group which is regardless of spatial proximity such as clans, a trade or an academic discipline. 'Transpatial groups work by analogy or identity rather than spatial contiguity. They overcome spatial separation, and integrate conceptually individuals that are spatially apart (Hillier, 1989, p. 16). Transpatial groups require to be realised in space through meetings 
and gatherings to intensify their solidarity. Spatial and transpatial realizations of community occur in space making space an intrinsic aspect of human activity. Hillier argues that cities are thus socio-spatial artefacts where such relations are realised. It is not a background of human activity. The way human societies order their space are reflections of these relations. 'Human societies order their spatial milieu in order to construct a spatial culture, [..] a distinctive way of ordering space so as to produce and reproduce not actual social relations but the principles for ordering social relations. Space is used sometimes to generate and sometimes to restrict the field of encounter of human beings and their symbols. Space is not simply a function of the principles of social reproduction: it is an intrinsic aspect of it, a necessary part of social morphology' (Hillier, 1989, p. 6).

When discussing spatial cultures, it is important to understand how they are dispersed in space. Their patterning of physical space reflects patterning of social space.

\section{Methodology}

Using space syntax method and Hillier's theories, the research methodology proceeds with a spatial research at two scales -the relationship of Soho with its surrounding areas at Global scale, and the other as analysing Soho within itself as a settlement at Local scale. At both scales, investigation maps the direction of changes in its physical space through a diachronic assessment of three historic periods, 1890, 1960 and 2018.

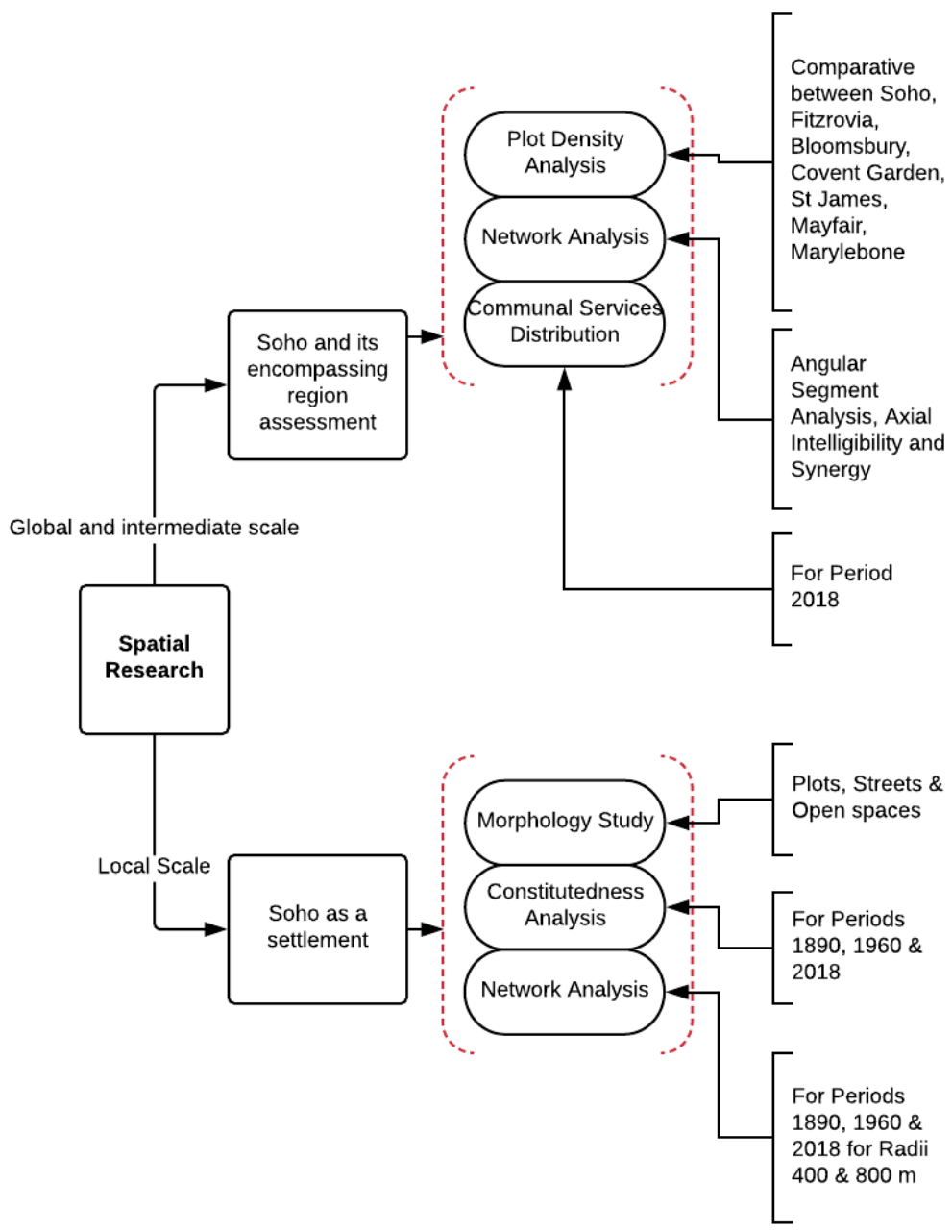

Figure 1: Structure of Methodology 


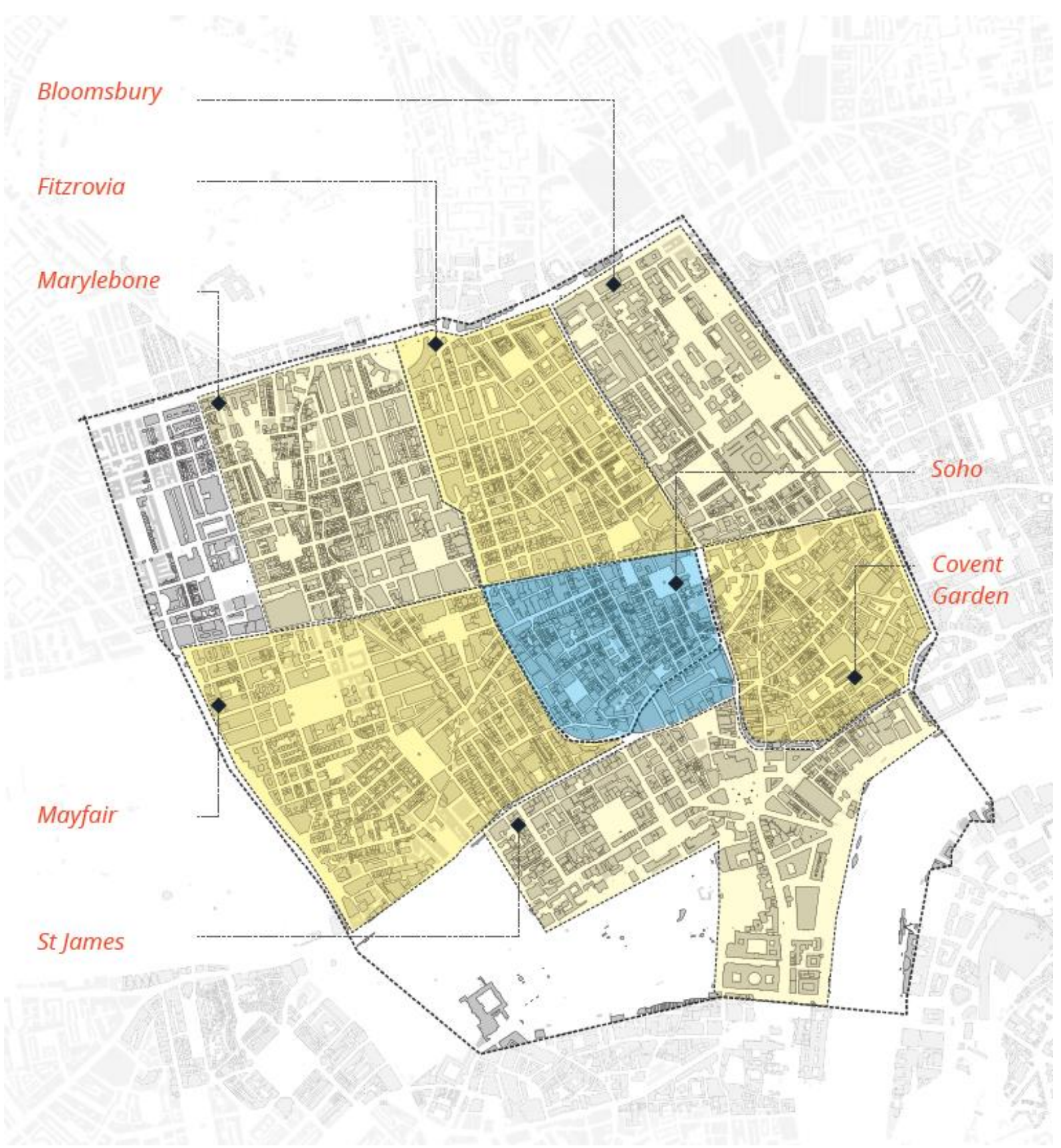

Figure 2: Perimeters considered for spatial research on Soho and surrounding region

\subsection{Global to Intermediate Scale}

Soho and the surrounding regions are comparatively analysed to identify the difference or similarities in spatial parameters. The study regions are Fitzrovia, Bloomsbury, Covent Garden, St James, Mayfair, Marylebone. These are not statistical boundaries but are as identified by the author. In the selection, two considerations were made - The high streets form the boundary between any two regions, segment values of high streets were included in both selections such that when analysing the values of segment and axial models, the values of common streets were added to both sections. 
Analysis of spatial parameters:

1. Plot density

It is the density of plots across the study area. High density implies a greater number of smaller plots. The building layer obtained from Open Street Maps was utilised for this analysis. It provides necessary information on condense or sparse distribution of buildings in the surrounding region and enables a comparison with Soho. Given that Soho is located in Zone 1, Central London, it is assumed that plot and building footprints are approximately equal.

2. Space syntax network analysis

Tested various network properties and a comparative result was produced for Soho, Fitzrovia, Bloomsbury, Covent Garden, St James, Mayfair, Marylebone, and the radii used are 400 and 2000. The network measures considered were as follows:

a) Angular Segment Measures - Choice and Integration.

Angular Choice is calculated by counting the number of times each street segment falls on the shortest path between all pairs of segments within a selected distance defined by the radius. It is the measure of to-movement and shortest path is the path which has the least angular deviation in the network. Routes that are longer and straighter higher choice value (Hillier et al., 1987).

Angular integration measures 'how close each segment is to all others in terms of the sum of angular changes that are made on each route' (Hillier and lida, 2005)

b) Normalised Choice and Integration

Normalising the values of Choice and Integration enables comparison between scales and grids. It eliminates the effect of high numbers of total depth or the sum of angular measures has on the overall values. The formulae applied are as follows (Al_Sayed et al., 2014, p. 117)

$$
\operatorname{NAIN}_{\theta}(x)=\frac{(n+2)^{1.2}}{\left(\sum_{i=1} d_{\theta}(x, i)\right)}
$$

where $d_{\theta}$ is the length of a geodesic (shortest path) between vertix $x$ and $i$. Normalised Angular Choice $\mathrm{NACH}_{\mathrm{B}}$ is defined as follows;

$$
N_{A C H}(x)=\frac{\log \left(\sum_{i=1}^{n} \sum_{j=1}^{n} \sigma(i, x, j)+1\right)}{\log \left(\sum_{i=1} d_{\theta}(x, i)+3\right)}(i \neq x \neq j)
$$

where $(i, x, j)=1$ if the shortest path from $i$ to $j$ passes through $x$ and 0 otherwise.

Figure 3: Formulae for normalising angular integration and choice

The datasets used for this analysis are courtesy of Digimaps Edina- for the Historical maps for periods 1890, 1960 and 2018 tracing which the model for analysis was generated, Space Syntax Lab - for the network models of London city, axial map of London- by permission of UCL EPRSRC Adaptable Suburbs Project (EP/I001212/1), and Open Street Map- provided data for TQ region of London has also been utilised with QGIS. This axial model was used to measure intelligibility and synergy.

\section{Landuse Analysis}

Existing landuses were mapped across Soho. Landuse data for the surrounding region was obtained from services of Ordnance Survey- Address Based Premium wherein a detailed classification of landuses were provided. This data was utilised to analyse the distribution of communal services around Soho. 


\subsection{Local Scale}

The analysis of Soho as a settlement involved micro morphological evolution of the area. Here the changes to the built environment over the three study periods c.1890, 1960, and 2018 were mapped. By comparing the changes, it was possible to view the pattern of change to the physical environment. This approach enables to answer question on how space has evolved over time and what it means in syntactic measures.

1. Morphology of plots, streets and open spaces

Plots, streets and open spaces (including alleys) were traced from historical maps for two periods- 1890 and 1960, provided by Digimaps Edina. Superimposing them on the current map of 2018 to identify changes in plot density for the region. Wherever the plots sizes and geometry differ from the 2018 (current modified map) it was marked in black. Refer Table 2.

\section{Constitutedness Analysis}

This is a method proposed by Hillier (1984, p.105-106). A constituted space is directly adjacent and permeable to a building. Entrances and exits to streets were mapped for the three study periods to identify street evolution as more or less constituted over time.

\section{Network Properties of Soho}

An Angular Segment Analysis (ASA) on the micro-network (street) of Soho for study periods were produced and tested for radii 400 and 800 , a proxy for less than 5 min walk distances. Smaller radii were selected as the diagonal of Soho is less than $1250 \mathrm{~m}$. Although, this method is not ideal for network analysis as it breaks the street segments from the larger network. The peripheral high streets act as barriers constricting the spread of landuses and other functions. The core argument of this research is this distinctness in function, character, and identity of Soho from its encompassing regions. Other scholars have studied high streets as causing this disjunction between regions dividing them into smaller regions (Vaughan et al., 2010; Griffiths, 2015). As this test focuses on centrality within Soho, these tests on local network should provide conclusive results.

\section{Findings}
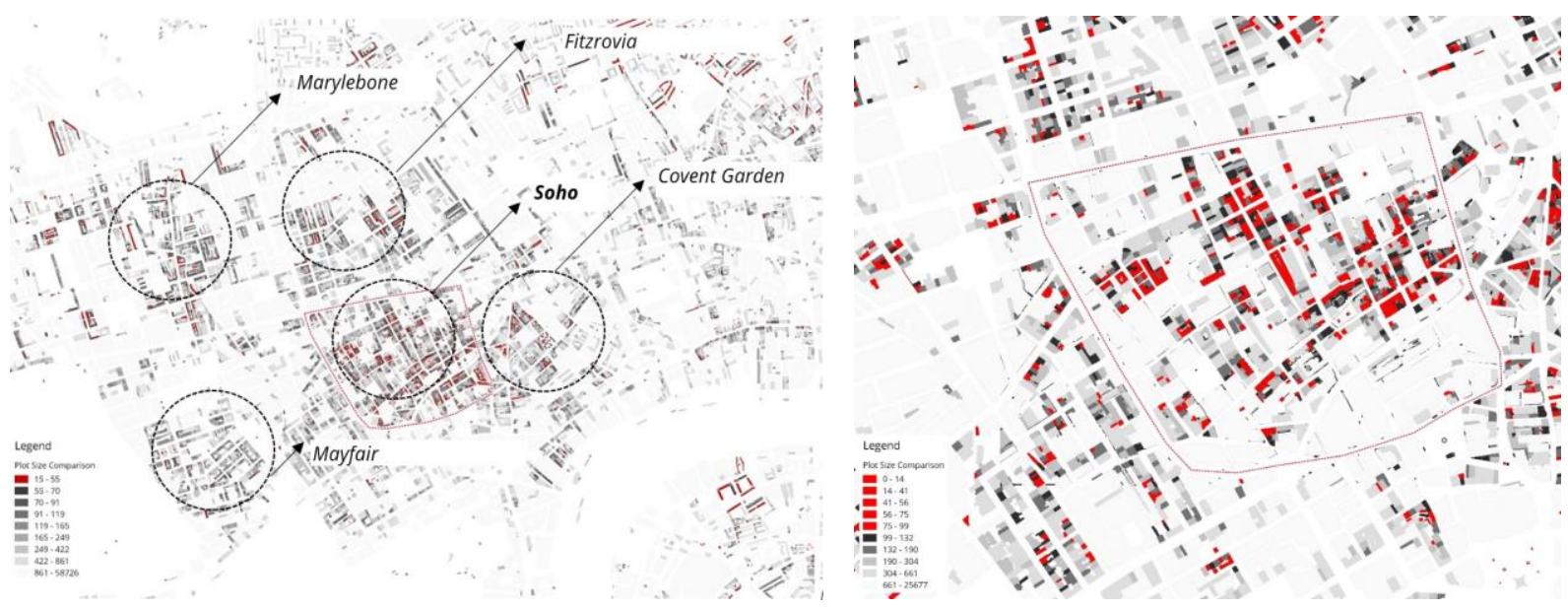

Figure 4: (Left) At Global Scale, Soho has higher plot density areas than surrounding cases; (Right) Highlighted in Red are the concentration of smaller plots along Old Compton, Wardour, Meard, Carnaby and parts of Greek and Frith Streets 


\subsection{Spatial Research: Comparison of spatial properties}

1. Morphology (Plots, Streets and Open Spaces) \& Constitutedness Analysis

Plot analysis indicate a larger concentration of smaller plots internally in Soho along Old Compton, Wardour, Meard, Carnaby and parts of Greek and Frith Streets. Along the peripheral high streets, plot density has reduced over time. These findings helped identify specific streets for further landuse investigations. Refer Table 6 for the criteria of selection.

Table 2: Summarises findings from spatial investigation

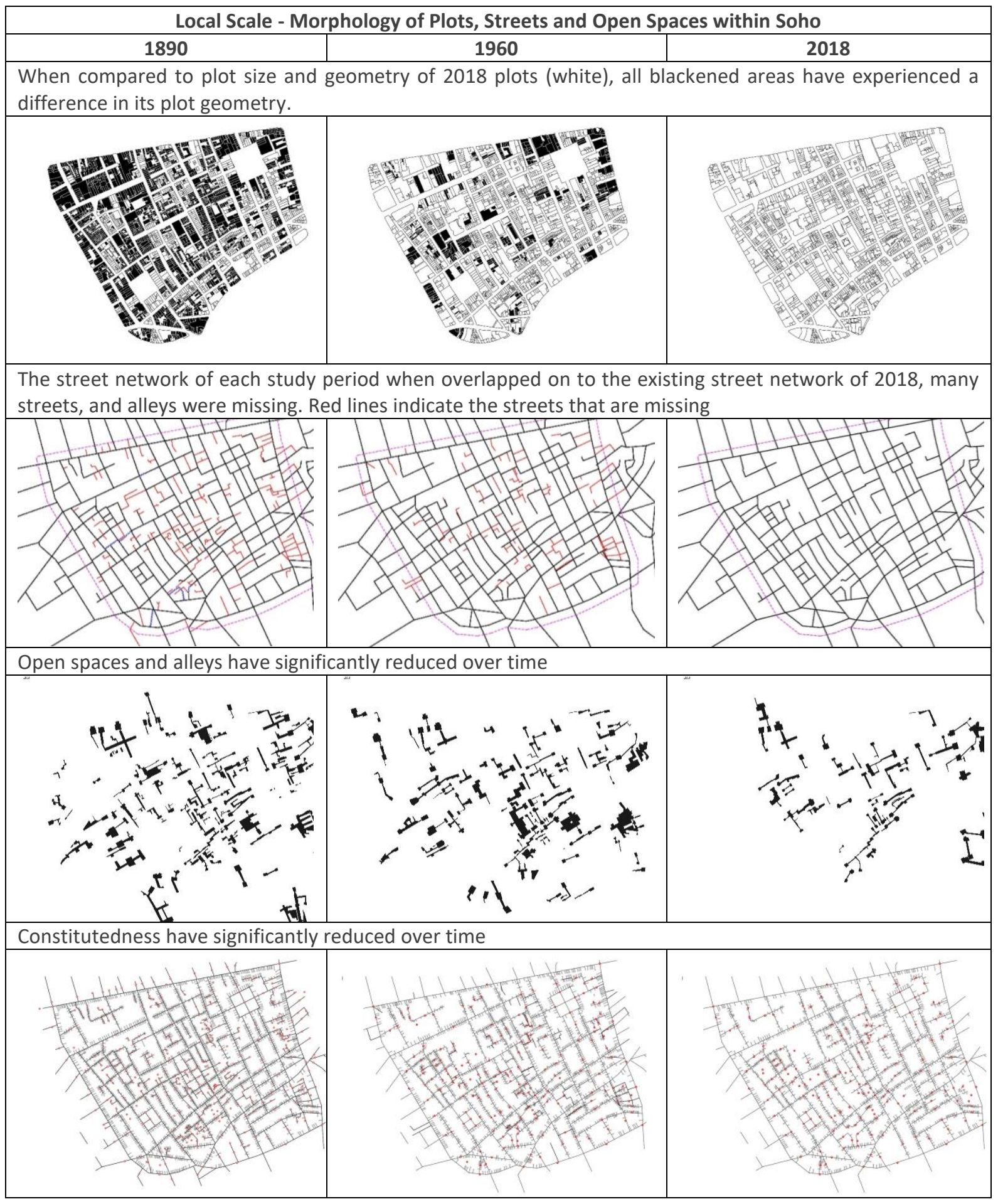


Table 3: Represents the number of missing plots and alleys from each period

\begin{tabular}{|l|l|l|l|}
\hline Year & $\begin{array}{l}\text { No. Of plots lost (absorbed } \\
\text { to form larger plots) }\end{array}$ & $\begin{array}{l}\text { No. Of streets and alleys lost } \\
\text { (absorbed to form larger plots) }\end{array}$ & Total no. Of open spaces \\
\hline 1890 & 2212 & 135 & 242 \\
\hline 1960 & 473 & 102 & 123 \\
\hline 2018 & - & - & 56 \\
\hline
\end{tabular}

\section{Street Network Analysis}

a. Angular Segment Analysis - Integration and Choice value tests

The tests followed to compare the values of spatial parameters of Soho against its surrounding:
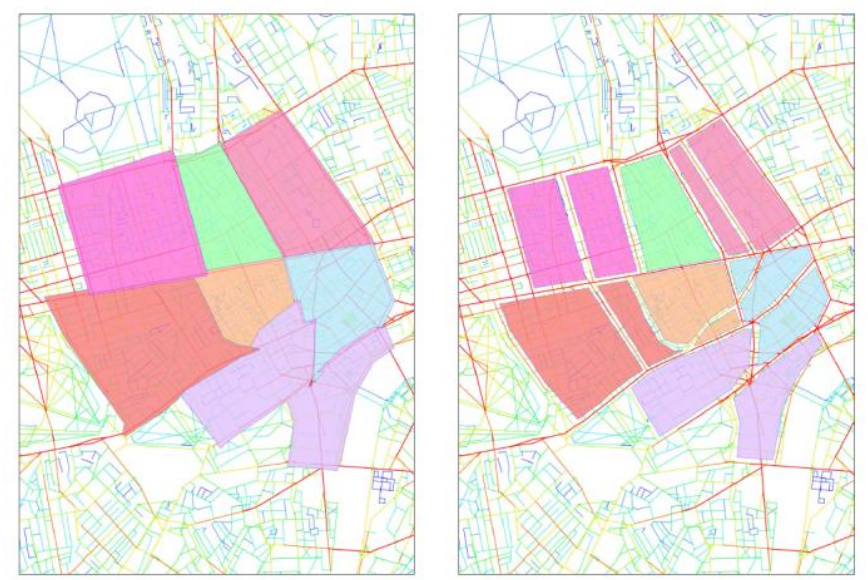

Figure 5: Left: External Boundary, Right: Internal Boundary

Test 1: Testing the average of all segment values of Soho region (whole) against similar of other regions

Refer Table 4. Results indicate for CHR400, 800, \& 2000, Soho's average street segment value is significantly higher than that of any of the surrounding regions. Street segments of Soho seem to benefit significantly from the surrounding high streets.

Test 2: Isolating internal segments (background network) of Soho and testing it against internal segments of other regions in question.

Refer Table 4. Results indicate Soho's value is second highest across all spatial parameters. The highest recorded was of Covent garden. Some streets within Covent Garden could not be identified as high street or internal streets and have been included in the data set. These streets have higher values and may have affected the average value. This is a limitation as the method chosen to identify high streets and internal streets is to some extend intuitive. The streets that run at the periphery of each of the regions were removed from the selection. Secondly, streets such as Shaftesbury avenue have also been removed from data set to avoid it affecting the average values, to give a proper indication of only background network values.

Refer Table 6. The network analysis was also performed at a smaller scale (within Soho) for study periods 1890, 1960 and 2018, in order to identify the streets that are central for movement and encounters. Choice and Integration are tested for smaller radii, R 800 and R 400. Top 10\% Streets are indicated in red and bottom $10 \%$ streets are indicated in blue. Refer Figure 5 and Figure 6 . Although it is not advised to extract a part of network without a buffer for segment analysis, this method is useful as it compares street network values over the three study periods within the same region and under the same 
boundary. It enables to view the shift in position of central streets of Soho's micro internal network over the years. The radii used for comparison across the different maps are also smaller which helps in analysing pedestrian movement pattern within Soho. For this project, it is important to understand the interaction potential afforded by the network over time and this comparative analysis enables to measure this change. Secondly, the selection of only local network of Soho for analysis was made because the perimeter is bound by high streets for all three study periods. An assumption is made that high streets may have limited the local activity concentrating these functions within the area. This may have also enabled in prosperity of local economy affording opportunities supported by the movement economy.

Table 4: Test 1 and 2 Results

\begin{tabular}{|c|c|c|c|c|c|c|}
\hline \multirow[t]{2}{*}{ AREAS } & \multicolumn{3}{|c|}{ Test1: All Street Segments } & \multicolumn{3}{|c|}{ Test 2: Internal Streets Segment Only } \\
\hline & CHR400 & CHR800 & CHR2000 & $\mathrm{CHr} 400$ & $\mathrm{CHr} 800$ & CHr2000 \\
\hline $\mathrm{SOHO}$ & 9331391.43 & 11613.32 & 127899.59 & 695343.00 & 12656.00 & 82100.00 \\
\hline FITZROVIA & 3265651.95 & 7327.19 & 102631.57 & 30399.00 & 2491.00 & 12138.00 \\
\hline BLOOMSBURY & 3341071.86 & 7409.80 & 104229.14 & 69858.00 & 3007.00 & 12787.00 \\
\hline COVENT GARDEN & 3171263.60 & 7240.69 & 100575.69 & 9485717.00 & 11743.00 & 319618.00 \\
\hline ST JAMES & 3182366.58 & 7217.21 & 100494.61 & 198227.00 & 3472.00 & 24610.00 \\
\hline MAYFAIR & 3264479.23 & 7324.70 & 102595.62 & 310228.00 & 1410.00 & 18278.00 \\
\hline \multirow[t]{2}{*}{ MARYLEBONE } & 3265260.15 & 7326.33 & 102619.39 & 12004.00 & 478.00 & 2582.00 \\
\hline & IN400 & IN800 & IN2000 & INTr400 & INTr800 & INTr2000 \\
\hline SOHO & 7355.30 & 324.98 & 1299.32 & 8502.95 & 361.54 & 1559.79 \\
\hline FITZROVIA & 6883.68 & 278.05 & 1193.64 & 6551.96 & 212.05 & 1072.70 \\
\hline BLOOMSBURY & 6891.87 & 278.08 & 1190.60 & 7583.25 & 276.82 & 1306.05 \\
\hline COVENT GARDEN & 6869.76 & 278.49 & 1197.98 & 9469.26 & 445.05 & 2210.78 \\
\hline ST JAMES & 6868.44 & 277.92 & 1196.08 & 6977.66 & 307.67 & 1238.29 \\
\hline MAYFAIR & 6883.39 & 278.01 & 1193.56 & 8214.47 & 223.16 & 1280.11 \\
\hline \multirow[t]{2}{*}{ MARYLEBONE } & 6883.47 & 278.03 & 1193.58 & 6909.11 & 190.33 & 921.08 \\
\hline & $\mathrm{NACHr} 400$ & NACHr800 & NACHr2000 & NACHr400 & NACHr800 & NACHr2000 \\
\hline $\mathrm{SOHO}$ & 0.9900 & 1.0500 & 1.0400 & 1.1365 & 1.1997 & 1.1609 \\
\hline FITZROVIA & 0.9500 & 1.0300 & 1.0100 & 0.8533 & 1.0518 & 0.9816 \\
\hline BLOOMSBURY & 0.9500 & 1.0300 & 1.0100 & 0.9333 & 1.0670 & 0.9923 \\
\hline COVENT GARDEN & 0.9400 & 1.0200 & 1.0000 & 1.3697 & 1.2254 & 1.3057 \\
\hline ST JAMES & 0.9400 & 1.0200 & 1.0000 & 1.0135 & 1.0240 & 1.0263 \\
\hline MAYFAIR & 0.9500 & 1.0300 & 1.0100 & 1.0652 & 0.9954 & 1.0401 \\
\hline \multirow[t]{2}{*}{ MARYLEBONE } & 0.9500 & 1.0300 & 1.0100 & 0.7799 & 0.8460 & 0.8350 \\
\hline & NAINr400 & NAINr800 & NAINr2000 & NAINr400 & NAINr800 & NAINr2000 \\
\hline $\mathrm{SOHO}$ & 1.7300 & 1.3600 & 1.5200 & 2.0021 & 1.4689 & 1.6694 \\
\hline FITZROVIA & 1.6200 & 1.4300 & 1.5000 & 1.5427 & 1.2705 & 1.4254 \\
\hline BLOOMSBURY & 1.6200 & 1.4300 & 1.5000 & 1.7856 & 1.4495 & 1.6371 \\
\hline COVENT GARDEN & 1.6200 & 1.4200 & 1.4900 & 2.2297 & 1.8213 & 2.0910 \\
\hline ST JAMES & 1.6200 & 1.4200 & 1.4900 & 1.6430 & 1.2872 & 1.3937 \\
\hline MAYFAIR & 1.6200 & 1.4300 & 1.5000 & 1.9342 & 1.3910 & 1.6798 \\
\hline MARYLEBONE & 1.6200 & 1.4300 & 1.5000 & 1.6268 & 1.2594 & 1.3931 \\
\hline
\end{tabular}


Table 5: Represents the graph analysis output of normalised choice (NACH) and Normalised integration (NAIN) for radii 400 (R400) and 800 (R800)

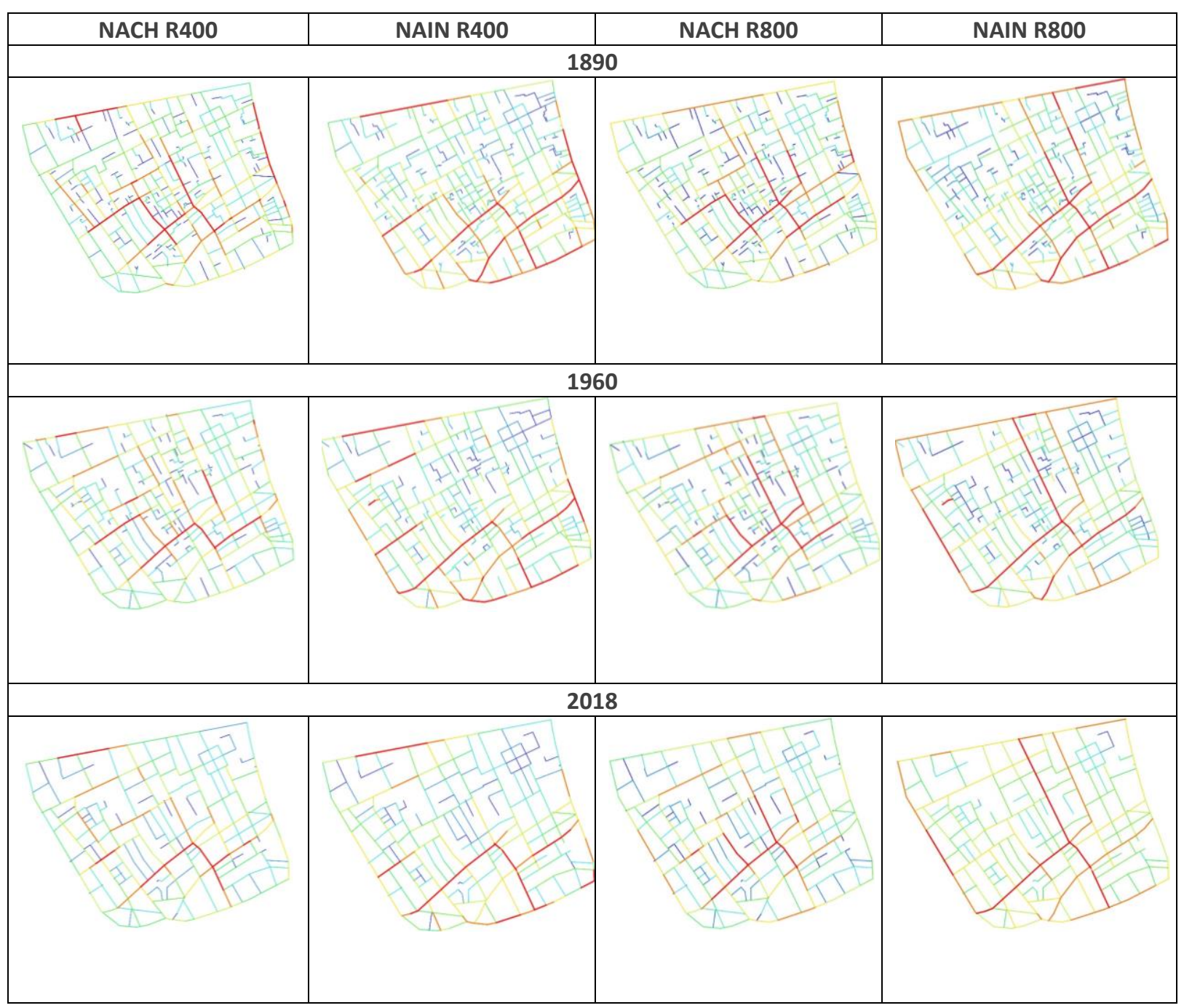

\subsection{Social research: Landuse Analysis}

Evolution of Landuse along selected streets were studied using Kelly's Directory Year - 1960, 1970, 1980, and 2018 Ground Floor Landuse. Refer Table 6 for selection criteria.

Some important observations from this analysis was the large concentration of singular type function along certain streets such as theatres along Shaftesbury Avenue, film and theatre production house along Wardour street, tailors and garment makers along Brewer Street, printers and supporting facilities along Old Compton street, etc.

Secondly, it was noticed that every space in Soho had a social function. The selection of smaller streets was a conscious decision. It indicated that streets that had poor access were still having multiple functions in the historical context. Meard Street for example in the earlier periods of 1950, 1960, 1970 each had multiple type of landuses. It now has only residential and access for loading and unloading, and one restaurant. Its function has reduced to just three. There is also ongoing debate about its identity as a residential spot and opposition by the residence society to protect Meard Street against gentrification as they oppose the imminent development of a retail store. This analysis shows that at any time in the past 
these spaces were part of multiple functions. The debate on its gentrification and multi-use type are meaningless.

Table 6: Indicates the no. of buildings that have direct access to a specified street, the constitutedness of the street in ascending order

\begin{tabular}{|c|c|c|c|c|}
\hline STREET NAME & C.1890 & c.1960 & c. 2018 & CRITERIA \\
\hline Walkers Court & 17 & 8 & 8 & Sexual identity \\
\hline Tisbury Court & 9 & 8 & 8 & $\begin{array}{l}\text { An alley near popular gay streets, present day many } \\
\text { massage parlours occupy this street }\end{array}$ \\
\hline Manette Street & 15 & 13 & 9 & $\begin{array}{l}\text { An important alley that connect Shaftesbury avenue to } \\
\text { Greek Street }\end{array}$ \\
\hline St Anns Court & 4 & 17 & 9 & Music identity \\
\hline Soho Street & 18 & 14 & 11 & Presence of a religious centre since 1960 's \\
\hline St Anns Yard & 4 & 16 & 15 & $\begin{array}{l}\text { A multi-purpose space used by many groups of people, } \\
\text { such as children of Soho Parish School, the ground for } \\
\text { Soho Village Fete, and also by public during the day as a } \\
\text { park and at night as pub-goers resting spot. }\end{array}$ \\
\hline Rupert Street & 23 & 16 & 16 & Gay identity \\
\hline Ramillies Place & 32 & 18 & 17 & $\begin{array}{l}\text { A pass-through street that has deteriorated in recent } \\
\text { years and failed as a public space although an attempt } \\
\text { was made to revive it adding benches and seating. }\end{array}$ \\
\hline Golden Square & 23 & 18 & 18 & Not actively used by public \\
\hline Meard Street & 27 & 19 & 19 & Residential identity \\
\hline Soho Square & 36 & 31 & 30 & $\begin{array}{l}\text { Active spot and always occupied by different groups of } \\
\text { people }\end{array}$ \\
\hline Broadwick Street & 78 & 49 & 43 & An old broad street used as a gathering point \\
\hline Poland & 76 & 50 & 48 & Polish identity, polish community \\
\hline $\begin{array}{l}\text { Great Marlbor- } \\
\text { ough }\end{array}$ & 95 & 60 & 53 & Tailors, retail shops \\
\hline
\end{tabular}

Figure 6: Graphs indicates the value of selected streets over historic periods

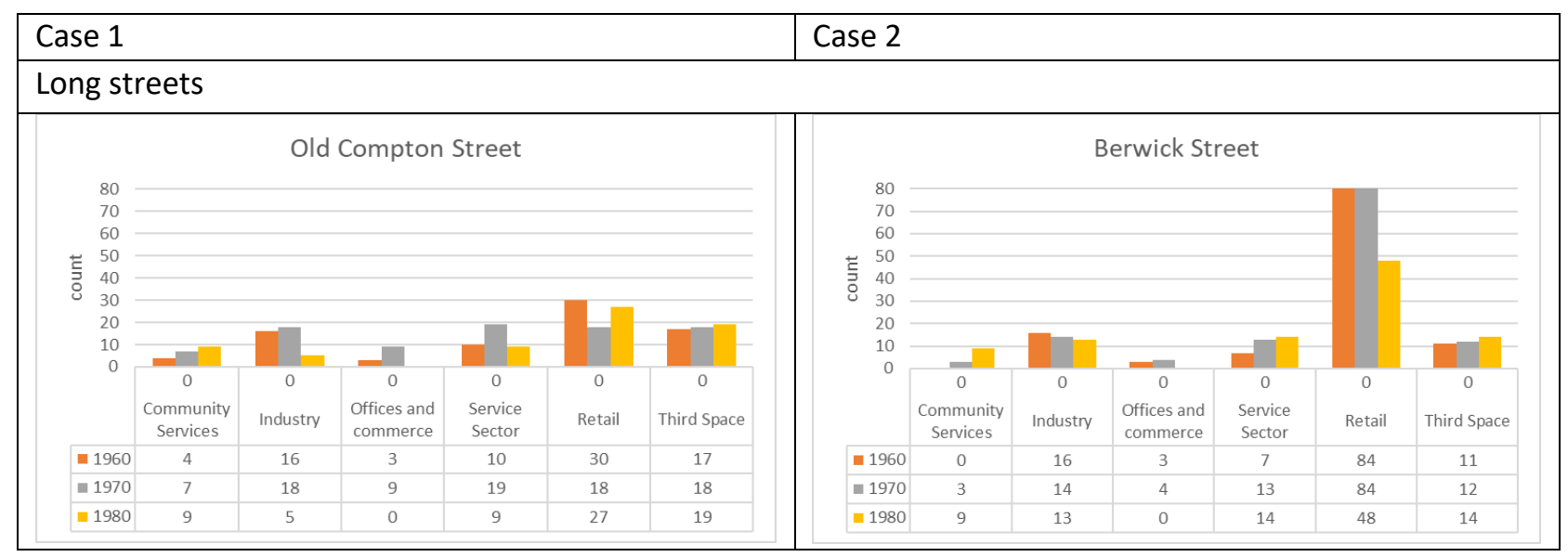




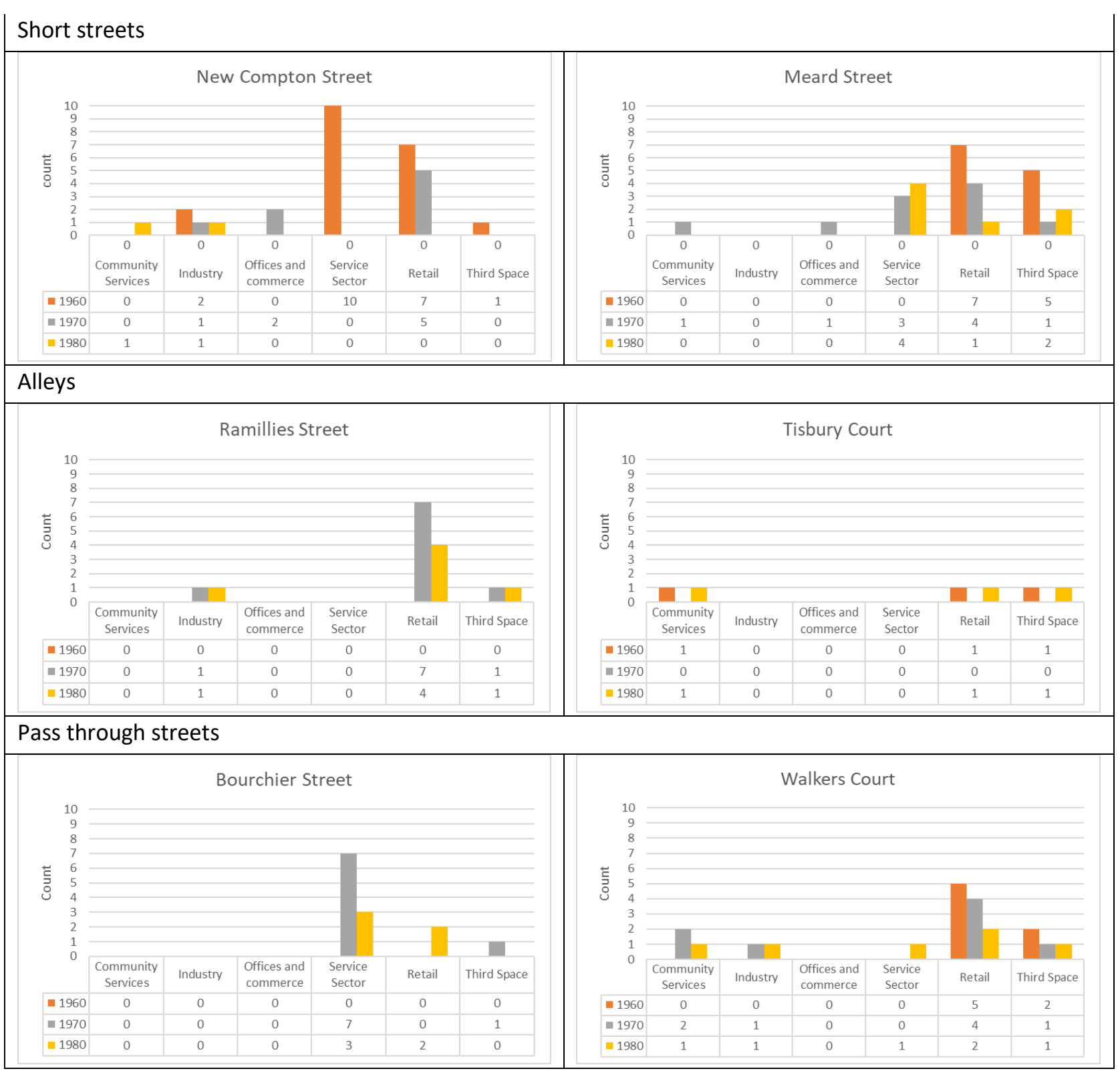

\section{Discussion}

\subsection{Evolution of Soho's as a true urban village}

The research findings indicate that Soho is unique from its surrounding areas such as Fitzrovia, Marylebone, Covent Garden, St James, Mayfair, and Bloomsbury in some of its morphological and syntactical aspects, which could explain why it developed as a unique space in the city.

The aggregate of smaller plots in Soho are significantly higher in comparison with its neighbouring regions and spread across the whole region. Jacobs (1961) has pointed out the importance of smaller plots in fostering diversity. Her notion of the 'intricate ballet of sidewalks' that sustain everyday noise strikes significant even to this day as a necessary factor for social cohesion. Smaller plots as contributing to foster social ecology and sustaining diversity has been discussed in many studies. Morphological diversity, Vaughan et al., (2015) suggests, has potential for propagating patterns of co-presence and encounter over time. Through a similar historical assessment, Vaughan et al. (2015, p. 99:17) points out that these smaller plots, buildings or building frontage cannot be assumed as the places of resilience but 
places where uses 'come and go [...] according to the changing scales of movement in and around it'. They afford this changeability. As plots consolidate to become larger plots, they lose this ability to adapt to changes due to constrains brought upon by the actual physical space which cannot afford multiple smaller uses. In Soho, the morphology of plots has significantly changed along the edges were high streets afford high through and to-movements. But the internal streets have a fair share of juxtaposition of small and bigger plots. It is also interesting to note that over the years the landuses that relate to music, immigrant businesses (such as Italian restaurants, Jewish tailors, Queer venues, fashion), these 'niche markets' appropriate streets with higher number of smaller plots.

Interpretation of Soho's network along space syntax analysis suggests Soho affords both microeconomic and socio-cultural activities. That is, the streets opportune many kinds of social functions. Soho's immigrant communities were agglomerated along certain streets (Speiser, 2017). They neither had to visit other streets, nor did they suffer for lingering onto their settlements. They neither had to visit other streets, nor did they suffer for lingering onto their settlements. Its communities prospered from its location in the global urban grid and continued to function as a true urban village. Oxford Street is the most integrated street in all of London. As a trickle-down effect, other linear and longer street segments that come off Oxford Street also have higher values and are among top 10\% among various syntactic measures. When compared to the surrounding areas such as Fitzrovia, Marylebone, Covent Garden, St James, Mayfair, and Bloomsbury were only a couple of streets are linear, long, and among top $10 \%$ of syntactic values, in Soho there seem to be a sort of network of streets with higher values. Together they form a mesh, with potential for high movement and encounter.

Soho's background spaces have evolved significantly over time from a space of social interaction and community building of a neighbourhood as in the 1800's to present day back alleys of a shopping district, theatre backstage entrances, garages, and so on. The most changes in social structure occurred along the peripheral streets such as Oxford Street and Regent Street. Plots sizes here have changed vastly over time than other parts of Soho. In the global network of London as a whole, Oxford Street has the highest value of space syntax measures global integration and choice, which means it is the most connected street in the connect and has the potential to bring in high through and to movement to the area. It could be said that change to these areas were brought about by the potential of network to afford that change.

For example, Soho did not evolve to become the china town of London, rather the culturally celebrated gay village of London. Vinod-Buchinger (2018)indicates that it could be connected back to the construction of Shaftesbury Avenue. China Town is the region in the south of Soho along Gerard Street. It has been split from Soho's main area by Shaftesbury Avenue constructed in 1886. China Town came to existence only since the 1960's when the Chinese settlers set up restaurants, stalls and businesses in the region. Gay identity of Soho is largely from the queer venues in the region. There are approximately 40 queer venues in Soho (significantly large concentration compared to rest of London) of which 22 of them are concentrated along Old Compton Street. The position and role of Old Compton Street in establishing this identity has been discussed in the previous report (Vinod-Buchinger, 2018). Viewing this through the layer of syntactic understanding of space as demonstrated in the research can answer some questions regarding identity and evolution of spaces. The identity of China Town since the appropriation by Chinese settlers remain undeterred. If all other external influences such as policy, or decision makers interferences are considered neutral, it could be suggested that the network has strongly influenced this areas generation as a Chinese communal space. It was large area functioning as an active background space. 


\section{Conclusion}

Space has the capacity to be structured or affect social structure. Hillier is successful in providing the connection of physical space as a perpetuation of social logic. His speculation on spatial cultures, therefore, enables a method to interact with these abstract ideas of space. The physical space is a generator of movement, a reflection of social relations and a constructor of social order (Hillier, 1989, 2016; Hillier and Vaughan, 2007). This research uses these notions to study the evolving nature of Soho in syntactic measures, there by exploring new ways to engage in social research. Hillier's spatial cultures is absolute and modest measure of interpretation that enables designers to not intervene but interact with social morphology based on evidences. Space syntax methods used in this research, have demonstrated through syntactic measures the relationship of spatial forms to social processes.

In conclusion, spaces and human relations are undoubtedly complex. This research hopes to have shared an interesting perspective on the spatiality of cultures and their interrelatedness to the evolving identity of Soho.

\section{References}

Al_Sayed, K. et al. (2014) Space Syntax Methodology. 4th Editio. Bartlett School of Architecture, UCL, London.

Collins, A. (2004) 'Sexual dissidence, enterprise and assimilation: Bedfellows in urban regeneration', in Urban Studies, pp. 1789-1806. doi: 10.1080/0042098042000243156.

Griffiths, S. (2015) 'The High Street as a Morphological Event', in Vaughan, L. (ed.) Suburban Urbanities: Suburbs and the Life of the High Street. London: UCL Press, pp. 32-50.

Hillier, B. et al. (1987) 'Creating Life: Or, Does Architecture Determine Anything?', Architecture et Comportement / Architecture and Behaviour, 3(3), pp. 233-250.

Hillier, B. (1989) 'The Archtiecture of Urban Object', Ekistics, pp. 5-21.

Hillier, B. (2007) Space is the machine: a configurational theory of architecture. Space Syntax.

Hillier, B. (2016) 'What are cities for? And how does this relate to their spatial form?', The Journal of Space Syntax, 6(2), pp. 198-212.

Hillier, B. and lida, S. (2005) 'Network and psychological effects in urban movement', Lecture Notes in Computer Science (including subseries Lecture Notes in Artificial Intelligence and Lecture Notes in Bioinformatics), 3693 LNCS(1987), pp. 475-490. doi: 10.1007/11556114_30.

Hillier, B. and Vaughan, L. (2007) 'The spatial syntax of urban segregation', Progress in Planning, 67(3), pp. 205-294. doi: 10.1016/j.progress.2007.03.001.

Jacobs, J. (1961) The Death and Life of Great American Cities. New York: Vintage Books/Random House.

Sheppard, F. H. W. (1966) 'Survey Of London', in Sheppard, F. H. . (ed.) Survery Of London Parish of St. Anne Soho. Greater London: The Athlone Press, University of London, pp. 1-17.

Speiser, P. (2017) Soho: The Heart of Bohemian London. British Library.

Vaughan, L. et al. (2010) 'The Spatial Signature of Suburban Town Centres', Journal of Space Syntax, 1(1), pp. 77-91. Available at: http://www.journalofspacesyntax.org/.

Vaughan, L. et al. (2015) 'An ecology of the suburban hedgerow, or: How high streets foster diversity over time', SSS 2015 - 10th International Space Syntax Symposium, pp. 1-19. Available at: http://www.scopus.com/inward/record.url?eid=2-s2.0-84959233012\&partnerID=tZOtx3y1.

Vinod-Buchinger, A. (2018) Gay Men and Gay Spaces - Unpublished. London. 